\title{
DEVELOPMENT OF ENERGY-EFFICIENT SHELL AND TUBE HEAT EXCHANGERS FOR USE IN GEOTHERMAL HEATING SYSTEMS
}

\author{
Djamal Chalaev ${ }^{1}$, Alex Shmatok ${ }^{1}$, Tatyana Grabova ${ }^{1}$, Nina Silnyagina ${ }^{1}$, \\ 1. Institute of Engineering Termophysics of National Academy of Sciences of Ukraine, \\ Kyiv 03057, Zhelyabov str. 2-a, e-mail: htplab@ukr.net
}

\begin{abstract}
- the results of studies of the intensity of heat transfer using thin-walled corrugated tubes of various modifications for working on model coolants that have an increased density and viscosity (a highly mineralized medium with a salt content of $250 \mathrm{~g} / \mathrm{kg}$ as the model coolants ) are presented in the paper.
\end{abstract}

Keywords: heat exchanger, corrugated tubes, discrete turbulizers, highly mineralized media.

\section{Introduction}

Currently, low mineralized thermal waters are mainly used in geothermal heating systems. Low mineralized thermal waters do not need additional water treatment and the development of special equipment. However, the reserves of such waters are small and may soon be exhausted. There is a drop in production wells in most cases.

The large-scale use of medium potential geothermal energy is primarily associated with the development of mineralized geothermal waters, which constitute a large part of the existing reserves. However, the content of a significant amount of dissolved salts and gases in them causes their high corrosiveness and tendency to scaling. As a result, one of the main problems with the use of such quality water is the development of methods to fight corrosion and scaling.

\section{Main material}

The main requirement for heat exchangers is a high heat transfer capacity and low loss in hydraulic resistance, and they must be compact and lightweight. It is necessary to take into account the properties of working media and the ability to work with polluted media, when solving standard heat engineering problems using heat exchangers. The cleaning of heat exchange equipment from contamination is the actual problem. Existing cleaning technologies are inextricably linked with labor costs, additional costs of fuel, chemical reagents, and environmental issues. To solve these controversial issues is possible only with the use of the latest developments and technologies that allow to obtain maximum heat exchange efficiency while reducing overall dimensions, as well as high reliability in operation and maintenance of heat exchangers.

Most of the existing heat exchange equipment does not take into account the properties of working medium, and therefore it is unstable. For example, plate heat exchangers are able to work exclusively with clean media, so one of the advantages of shell-and-tube heat exchangers is that they do not need a clean working media, and can work effectively with media that have a varied chemical composition and increased viscosity.

The problem of using highly mineralized media as a heat carrier is scaling on the heat exchange surface of the heat transfer wall, which increases the thermal resistance and reduces the heat transfer coefficient of the heat exchangers.

In the search for methods of intensification of heat exchange processes, studies of foreign and domestic scientists are constantly monitored. Currently, the passive methods of intensification of heat transfer and, in particular, the developed heat exchange surfaces are widely used. So far, no universal methods and criteria have been developed for evaluating the effectiveness of heat exchange surfaces. It is needed further study of thermal and hydrodynamic processes occurring in developed heat exchange surfaces in order to obtain generalized dependencies for calculating thermal and hydraulic characteristics and evaluating their effectiveness. 
Choosing for practical application of heat transfer intensification method, it is necessary to take into account not only the efficiency of the surface itself, but also its manufacturability, the manufacturability of the apparatus, the strength requirements and the surface pollution.

Domestic industry produces flexible stainless corrugated tubes of small diameter. Such heat exchange surface is characterized by compactness, low specific cost, the ability to create complex heat exchange surfaces due to the "bend" of the heat exchange surface and the twist of the bundle of corrugated tubes. Corrugated tubes provide turbulence near the surface of the tube wall, thereby reducing the thickness of the thermal boundary layer. As a result, the mixing of the fluid near the tube wall is improved, due to the separation perturbations from the wall to the main flow, thus increasing the overall heat transfer coefficient in the heat exchange systems. Creating a selfoscillation mode of the heat exchange tubes during fluid movement prevents the formation of deposits on the walls of the tubes, thereby solving the actual problem of contamination of the heat exchange equipment.

The results of theoretical and experimental studies of the intensity of heat transfer using thinwalled corrugated tubes of various modifications to work on model heat transfer media with an increased density and viscosity (mineralized solution with a salt content of $250 \mathrm{~g} / \mathrm{kg}$ as a model medium) are presented in the paper [1, 2]. Comparative analysis of operating modes of a heat exchanger with a corrugated inner tubes of various modifications and a heat exchanger with a smooth inner tubes when working on model coolants showed that, despite the increased density and viscosity, highly mineralized solution compared to water, corrugated tubes form an efficient turbulization of the near-wall layer and provide high heat transfer coefficients. On the basis of the obtained data, an effective heat exchanger is created (Fig. 1). The heat exchanger consist of thinwalled flexible stainless steel corrugated tubes as heat-exchanging elements, which are able to work with different chemical composition media and increased viscosity. This heat exchanger is designed to solve standard heat engineering problems taking into account the properties of working media.

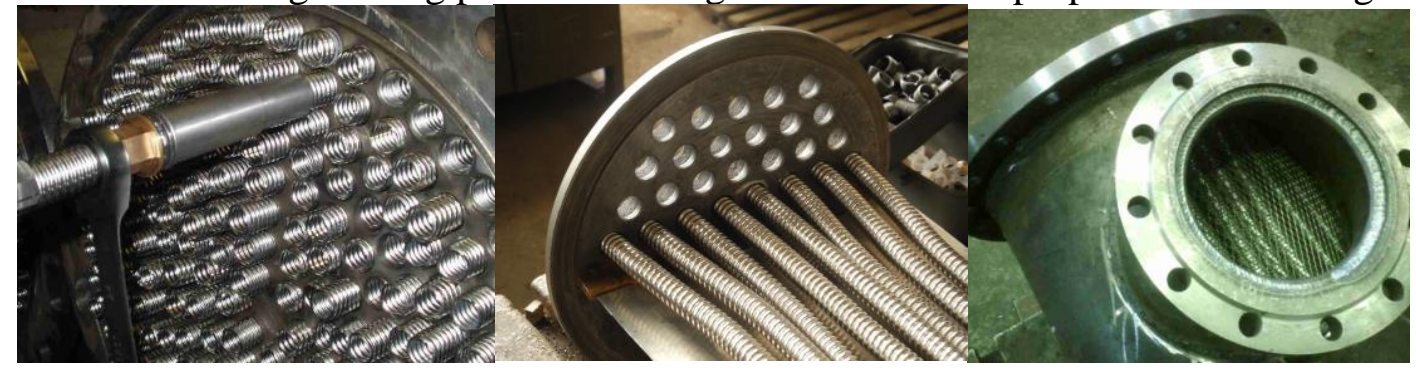

Fig.1. Shell-and-tube heat exchanger with corrugated tubes

\section{Conclusion}

The use of flexible stainless corrugated tubes in heat exchangers allows to create high flow turbulence at relatively low coolant velocities, provides high heat transfer coefficients in the apparatus even when using highly mineralized and viscous media. The results of the study of an experimental sample of a tubular heat exchanger and the achieved values of the heat transfer coefficient (more than $3000 \mathrm{~W} / \mathrm{m} 2 \cdot \mathrm{K}$ with a coolant mineralization of about $250 \mathrm{~g} / \mathrm{kg}$ ) illustrate the potential of the proposed approach and can be used to calculate and design heat exchangers intended for use in power engineering and geothermal power engineering.

\section{References}

1. Hrabov L.M., Chalaev L.M., Pereiaslavtseva E.A., Sylniahyna N.B., (2014), Razrabotka konkurentnosposobnikh trubchatykh teploobmennikh apparatov, Naukovi pratsi ONAKhT, 2(45), pp. 93-97.

2. Dolinskyi A.A., Chalaev D.M., Hrabov L.N., Pereiaslavtseva O.O., Sylniahina N.B., Kovalov V.V.(2013), Rozrobka efektyvnykh teploobminnykiv novoho pokolinnia na osnovi trub z dyskretnymy turbulizatoramy, Enerhetyka ta elektryfikatsiia, 4(13), pp.28-33. 